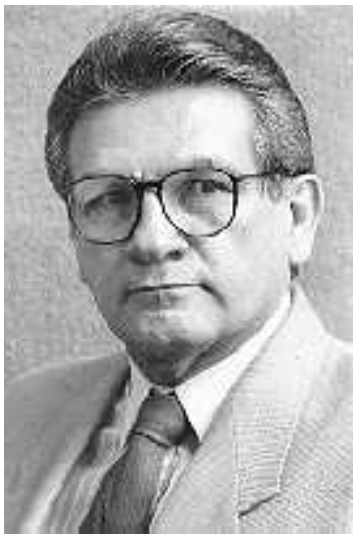

\title{
HOMENAGEM Prof.Dr. JOSÉ ALBERTO MELLO DE OLIVEIRA
}

Nascido aos 29 de março de 1937, na cidade de Sales de Oliveira, São Paulo, ingressou no primeiro ano do curso médico da Faculdade de Medicina de Ribeirão Preto-FMR P-USP, como aluno da quinta turma de graduação em Medicina, do ano de 1956.

Como aluno de Medicina, participou de uma atividade de estágio voluntário com o Prof. Walter August Hadler, no Departamento de Histologia e Embriologia, quando teve participação, pela primeira vez, em um trabalho científico.

Trabalhou como clínico geral na cidade de Bocaina, São Paulo, por dois anos.

Em 1963, procurou o Prof. Fritz Köberle para um estágio no Departamento de Patologia da FMRPUSP. Naquela época, não havia o curso de residência médica em Patologia, o que motivou o pedido de estágio. Foi convidado pelo Prof. Köberle a ingressar na carreira universitária em setembro de 1963, permanecendo nela até sua aposentadoria em 1998.

Durante sua permanência, teve intensa participação nas atividades administrativas, no Departamento de Patologia, como Chefe e Suplente da Chefia, Coordenador da Área de Concentração Patologia, Comissão de Orçamento da FMRP-USP, Coordenador do Serviço de Patologia do Hospital das Clínicas da Faculdade de Medicina de Ribeirão Preto da Universidade de São Paulo - HCFMRP-USP e membro do Conselho Deliberativo do HCFMRPUSP, dentre outras.

A história do Prof. José Alberto se confunde com a do Departamento de Patologia, dada sua participação em algumas conquistas tais como: Organização dos Programas de Pós-graduação "strictu sensu" da Área de Concentração "Patologia Humana" e reorganização dos Serviços de Verificação de Óbitos do Estado de São Paulo.
Orientou e coorientou vários alunos em nível de Mestrado e Doutorado, sendo dois deles atuais docentes do Departamento de Patologia.

Desenvolveu várias linhas de pesquisa, a saber: Patogênese da Cardiopatia Chagásica, Histoenzimologia em Cardiopatias Humanas e Experimentais, Histoenzimologia da Esteroidogênese e Histoenzimologia Aplicada à Patologia Cirúrgica e Necroscópica.

Publicou cerca de cem artigos, entre nacionais e internacionais. Portador de memória extraordinária para narrar fatos distantes, publicou vários artigos, descrevendo a história do Departamento de Patologia, contando fatos pitorescos e marcantes da época vivida junto ao Prof. Köberle, fundador do Departamento de Patologia.

Seu trabalho na área de Histoenzimologia rendeu-lhe o título de Assistant-Étranger por ocasião de seu Pós-Doutorado na Universidade de Paris.

Mesmo aposentado, após trinta e cinco anos de trabalhos prestados à Faculdade de Medicina de Ribeirão Preto, o Prof. José Alberto continua em atividade no Departamento de Patologia, presente uma vez por semana na sala de necrópsias do HCFMRP-USP, supervisionando o Laboratório de Histoenzimologia, no Departamento de Patologia, sob sua responsabilidade, e narrando suas lembranças sobre situações ocorridas no Departamento de Patologia com extrema riqueza de detalhes e com o cavalheirismo que lhe é peculiar.

Prof. Dr. ROBERTO SILVA COSTA

Chefe do Departamento de Patologia da FMRP-USP

e-mail: rscosta@fmrp.usp.br

REGINA MARA C. FARIA BUENO

Secretária do Departamento de Patologia da FMRP-USP e-mail: regbueno@fmrp.usp.br

Fone/Fax: $0 * * 166331068$ 